\title{
Analysis of air quality changes during the COVID-19 in Wuhan city based on Over-standard multiples method and Gray relational analysis
}

Junhong Ji

Liaoning Technical University

Runqi Chang ( $\nabla$ amandarq@qq.com )

Liaoning Technical University https://orcid.org/0000-0002-6802-942X

\section{Research Article}

Keywords: COVID-19, Air quality, Gray relational analysis, Wuhan, Pollutant

Posted Date: September 25th, 2020

DOI: https://doi.org/10.21203/rs.3.rs-34041/v3

License: (c) (i) This work is licensed under a Creative Commons Attribution 4.0 International License.

Read Full License 


\section{Abstract}

To study air quality changes during the COVID-19. This paper introduced the Over-standard multiples method and Gray relational analysis to study the individual and overall change trends of pollutants in Wuhan during the same period in the past seven years. The result shows that the concentrations of $\mathrm{SO}_{2}$ and $\mathrm{O}_{3}$ increased but still meet the standard. However, the pandemic promoted a decrease in $\mathrm{PM}_{2.5}, \mathrm{PM}_{10}$, and $\mathrm{NO}_{2}$ concentrations, but it had just reached the standard or even exceeded the standard. This article discussed the feasibility of using Gray relational analysis to analyze pollutants exceeding the standard from an overall perspective and provided new ideas for future research.

\section{Introduction}

In December 2019, unknown pneumonia patients appeared in Wuhan. The study found that it was caused by a new coronavirus. World Health Organization (WHO) named the new coronavirus-infected pneumonia as COVID-19. Nowadays, it has spread globally and presents a pandemic trend. (https://www.who.int/). To control the pandemic, many countries carried out isolation blockade which reduces people's social activities and prompted companies to stop production. These have a directly influence on air quality. On the contrary, air pollutants can also affect virus transmission even some health issues (Brandt et al. 2020; Ciencewicki and Jaspers 2007). Hence, it is pretty essential to study air quality changes during the COVID-19 pandemic.

Contemporarily, many scholars have carried out relevant researches in the world. (Dantas et al. 2020; Lal et al. 2020; Li et al. 2020; Nakada and Urban 2020) found that the lockdown reduces the emissions of $\mathrm{SO}_{2}, \mathrm{NO}_{x}, \mathrm{PM}_{2.5}, \mathrm{CO}, \mathrm{VOCs}$, and AQI, even low-to-moderate reduce Aerosol Optical Depth obviously in the corresponding research region. But at the same time, some of them found that ozone increased distinctly. Similarly, (Kerimray et al. 2020) indicated the concentrations of $\mathrm{NO}_{2}, \mathrm{PM}_{2.5}$, and $\mathrm{CO}$ reduced obviously. But the concentrations of $\mathrm{O}_{3}$, benzene, and toluene were higher than those before lockdown in Almaty. In the above study, scholars have applied a variety of research methods, such as utilizing the cokriging method in ArcGIS, applying the WRF-CAMx modeling system, analyzing pollutants concentrations changes directly, and so on. However, few scholars have applied the Gray relational analysis (GRA) to analyze the changes in air quality during the pandemic.

Not only the trend of air quality changes but also the situation of excess air pollutants is worthy of attention. Analyzing the situation of exceeding air pollutants can help staff find the degree of pollution directly and improve air quality more efficiently. Considering that the basic idea of GRA is to reflect the degree of correlation between systems by calculating the gray relational degrees (GRD) between systems, this paper intended to apply GRA to calculate the GRD between the actual concentration of air pollutants and the concentration limit sequence which reflects the situation of exceeding air pollutants, and then discussed the changes in pollutant concentration during the COVID-19. 
Furthermore, to prove the feasibility of GRA, this paper introduced an Over-standard multiples method (OSM) to analyze the exceeding standard situation and changing trend in the six monitoring pollutants while found that the main pollutants are $\mathrm{PM}_{2.5}$ and $\mathrm{PM}_{10}(\mathrm{PM})$. And then, this paper utilized GRA to analyze the concentration changes of PM and compared it with the result of OSM. The results showed that it is feasible to use GRA to analyze the changing trend of air pollutants and the exceeding standard situation. This paper not only analyzes the changes in air quality during the pandemic but also provides new ideas for analyzing the overall changes in the pollutants exceeding the standard.

\section{Statistics Date And Data}

\section{Statistics date}

The period analyzed in this article is the first two months of the pandemic. However, it was during the Spring Festival (SF). Generally, people's behavior during the Spring Festival has strong stage characteristics. People's trip frequency and the possibility of setting off firecrackers will increase. Companies will stop production. These staged behaviors during SF will affect air quality to some extent. Aiming to avoid the impact on the analysis, this article took the Chinese New Year's Eve (NYE) as a breakpoint, and regarded the two months corresponding to the 15 days before and after the NYE's calendar date in the past seven years as the same period.

\section{Data sources}

This paper collected data from the Department of Ecology Environment of Hubei Province (http://sthjt.hubei.gov.cn/), Wuhan Ecology and Environment Bureau (http://hbj.wuhan.gov.cn/) and "Atmosphere 110" platform (http://daqi110.com/index.html).

\section{Statistical data and reference standard}

The air quality assessment project discussed in this article is $\mathrm{PM}_{2.5}, \mathrm{PM}_{10}, \mathrm{SO}_{2}$ and $\mathrm{NO}_{2}$, the 95 th percentile of the daily average of $\mathrm{CO}(\mathrm{CO})$, and the 90th percentile of the maximum daily average concentration of $\mathrm{O}_{3}$ for 8 hours $\left(\mathrm{O}_{3}\right)$. The actual data is shown in Table 1 .

This article took the Chinese GB3095-2012 Environmental Air Quality Standards as a reference standard(₫Environmental Air Quality Standards₫GB3095-2012邓2012).

Table 1 Pollutant concentrations and corresponding reference standards for concentration limits in Wuhan during the same period in 2014-2020 


\begin{tabular}{|lllllll|}
\hline Statistics Date & $\mathrm{PM}_{2.5}$ & $\mathrm{PM}_{10}$ & $\mathrm{SO}_{2}$ & $\mathrm{NO}_{2}$ & $\mathrm{CO}$ & $\mathrm{O}_{3}$ \\
& $\left(\mu \mathrm{g} \cdot \mathrm{m}^{-3}\right)$ & $\left(\mu \mathrm{g} \cdot \mathrm{m}^{-3}\right)$ & $\left(\mu \mathrm{g} \cdot \mathrm{m}^{-3}\right)$ & $\left(\mu \mathrm{g} \cdot \mathrm{m}^{-3}\right)$ & $\begin{array}{c}\left(\mathrm{mg} \cdot \mathrm{m}^{-}\right. \\
\left(\mu \mathrm{g} \cdot \mathrm{m}^{-3}\right)\end{array}$ & \\
\hline 2014.1 & 185 & 192 & 57 & 82 & 2.3 & 95 \\
\hline 2014.2 & 91 & 84 & 21 & 45 & 2.1 & 64 \\
\hline 2015.2 & 110 & 119 & 24 & 59 & 2 & 98 \\
\hline 2015.3 & 100 & 100 & 21 & 53 & 1.5 & 101 \\
\hline 2016.1 & 107 & 122 & 21 & 49 & 2 & 76 \\
\hline 2016.2 & 94 & 121 & 20 & 43 & 1.8 & 112 \\
\hline 2017.1 & 90 & 113 & 14 & 54 & 1.8 & 73 \\
\hline 2017.2 & 73 & 96 & 14 & 57 & 1.6 & 100 \\
\hline 2018.2 & 68 & 94 & 12 & 54 & 1.5 & 96 \\
\hline 2018.3 & 50 & 83 & 9 & 57 & 1.4 & 128 \\
\hline 2019.1 & 94 & 104 & 9 & 56 & 1.8 & 70 \\
\hline 2019.2 & 64 & 72 & 7 & 35 & 1.4 & 67 \\
\hline 2020.1 & 60 & 70 & 7 & 37 & 1.4 & 80 \\
\hline 2020.2 & 38 & 46 & 8 & 21 & 1.2 & 102 \\
\hline $\begin{array}{l}\text { Reference standards for } \\
\text { concentration limits }\end{array}$ & 35 & 70 & 60 & 40 & 4 & 160 \\
\hline
\end{tabular}

\section{Methodology}

\section{Method of over-standard multiples}

To analyze the specific situation of each pollutants and provide a reference basis for verifying the results of GRA, this article introduced the method of over-standard multiples. The OSM is the ratio of the over-standard concentration and the concentration limit. The OSM reflects the degree of overcontamination of pollutants. The calculation formula is as follows:

$$
\omega_{k}=\frac{R_{k}-L_{k}}{L_{k}}
$$


In Eq. (1), $\omega_{k}$ represents the kth pollutant's OSM. $R_{k}$ represents the kth pollutant's actual concentration and $L_{k}$ is the kth pollutant's reference standard for concentration limit.

\section{Gray relational analysis}

Gray relational analysis is part of the gray system theory (Morán et al. 2006) and can be used to describe the degree of correlation or similarity between systems. With applying to small sample size $(\geq 4)$, GRA is more widely used. The main steps are as follows:

1) Establish the original data matrix and dimensionless it.

2) Select a sequence that can be regarded as a comparison standard, called the reference sequence. The sequence of other evaluated objects is called the comparison sequence.

3) Calculate the GRD between the comparison sequence and the reference sequence, which directly reflects the correlation degree between them.

The greater the GRD, the stronger the correlation, that is, the higher the similarity.

\section{Case Study}

\section{Analysis of exceeding the standard of air pollutants in Wuhan}

It can be seen from equation 1 that the OSM not only reflects whether the pollutant exceeds the standard but also reflects the degree of the pollutant exceeding the standard. When the OSM is positive, it means the pollutant is over-standard. When it is negative, it means that the pollutant meets the requirements and does not exceed the standard. The greater the OSM, the greater the degree of pollutants exceeding the standard. Applying the collected sample data to calculate the OSM of the corresponding air pollutants in Wuhan, the results are shown in Figure 1. $\mathrm{PM}_{2.5}, \mathrm{PM}_{10}, \mathrm{SO}_{2}$, and $\mathrm{NO}_{2}$,

As shown in Figure 1, analysis of the overall change trend revealed that the OSM of most of the pollutants have decreased compared with 2014 , that is, the concentration of pollutants has dropped. Compared with last year, the OSM of $\mathrm{O}_{3}$ in the first month and the $\mathrm{SO}_{2}$ and $\mathrm{O}_{3}$ in the second month have increased, but it is still negative, which means that although the concentration of these pollutants has increased this year, but still meet the standards. The OSM of CO is reduced and remains negative, that is, the concentration of $\mathrm{CO}$ is still in compliance with the standard. The OSM of $\mathrm{NO}_{2}$ has decreased, that is, the concentration has decreased, and in the past two years, there has been a tendency to transition to the standard state. As for $\mathrm{PM}_{10}$ and $\mathrm{PM}_{2.5}$, although their OSM decreased, they only showed a positive value in February 2020. Over the past seven years, the OSM of $\mathrm{PM}_{10}$ and $\mathrm{PM}_{2.5}$ has been relatively large, which means that the main pollutant in Wuhan is $\mathrm{PM}_{10}$ and $\mathrm{PM}_{2.5}(\mathrm{PM})$. Hence, this article focuses on the GRA of PM. 
To explore the feasibility of applying GRA to analyze the change of air pollutant concentration, this paper conducted a grey correlation analysis on the concentration change of the main pollutants-PM in Wuhan.

In this article, regarding the concentration limits as a reference sequence, and the pollutant concentrations on the statistics date as comparative sequences, the GRD of them directly reflects the air quality. The greater the GRD, the better the air quality. This article takes PM as an example for GRA, and the results are shown in Figure 2.

As shown in Figure 2, according to the change trends of GRD, it is found that the GRD of PM has increased significantly compared with 2014. Comparing with last year, the situation is the same. These trends are consistent with the results of OSM analysis, which shows that it is feasible to apply GRA to analyze the change trend of pollutants

\section{Discussion And Conclusions}

(1) In terms of methods, the OSM can not only show the trends of pollutant concentration changes but also intuitively show the degree of pollutants exceeding the standard.

(2) When GRA is used to analyze the changing trend of pollutant concentration from an overall perspective, the analysis result is good for a single whole.

(3) From the perspective of pollutant concentrations, during the COVID-19 pandemic, the concentrations of $\mathrm{O}_{3}$ and $\mathrm{SO}_{2}$ mainly showed an upward trend, especially in the second month, that is, after the lockdown. The increase in $\mathrm{O}_{3}$ concentration could be due to the decrease in PM and NOx (Sharma et al. 2020). Although some enterprises stopped production in the second month, considering the increase in $\mathrm{SO}_{2}$ concentration mainly related to industrial emissions in China(Wang. and Huang. 2015), it may be that the sharp increase in shipments of medical products and medical wastes led to an increase in $\mathrm{SO}_{2}$ concentration. Of course, there may be meteorological reasons, this article does not do an in-depth discussion

(4) According to the result of GRA, the situation of pollutants exceeding the standard had improved. However, it should be noted that although the concentrations of $\mathrm{PM}_{2.5}$ and $\mathrm{PM}_{10}$ had decreased, it is still close to or even exceeded the limits.

(5) During the epidemic, the main pollutant in Wuhan was still PM, which has not changed in the same period in the past seven years.

(6) some scholars have pointed out that when the society fully resumes and the economy recovers, the improvement in air quality will not last forever, or even worse than before the pandemic (Quirin 2020; Wang and Su 2020). Hence, scholars should learn from the experiences during the pandemic and formulate environmental protection measures suitable for normal implementation. 


\section{Declarations}

\section{Consent for publication}

Written informed consent for publication was obtained from all participants.

\section{Availability of data and materials}

All data in this article can be obtained from: http://dx.doi.org/10.17632/k5tcg8btbz.4.

\section{Competing interests}

The authors declare no known competing for financial interests or personal relationships that could have appeared to influence the work reported in this paper.

\section{Funding}

This study was financially supported by the Department of Education of Liaoning Province Fund (NO. LJ2019JL016).

\section{References}

1. Brandt EB, Beck AF, Mersha TB (2020) Air pollution, racial disparities and COVID-19 mortality J Allergy Clin Immunol doi:10.1016/j.jaci.2020.04.035

2. Ciencewicki J, Jaspers I (2007) Air pollution and respiratory viral infection Inhal Toxicol 19:11351146 doi:10.1080/08958370701665434

3. Dantas G, Siciliano B, Franca BB, da Silva CM, Arbilla G (2020) The impact of COVID-19 partial lockdown on the air quality of the city of Rio de Janeiro, Brazil Sci Total Environ 729:139085 doi:10.1016/j.scitotenv.2020.139085

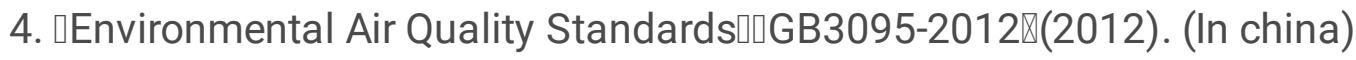

5. Kerimray A, Baimatova N, Ibragimova OP, Bukenov B, Kenessov B, Plotitsyn P, Karaca F (2020) Assessing air quality changes in large cities during COVID-19 lockdowns: The impacts of traffic-free urban conditions in Almaty, Kazakhstan Sci Total Environ 730:139179 doi:10.1016/j.scitotenv.2020.139179

6. Lal P et al. (2020) The dark cloud with a silver lining: Assessing the impact of the SARS COVID-19 pandemic on the global environment Sci Total Environ 732:139297 doi:10.1016/j.scitotenv.2020.139297

7. Li L et al. (2020) Air quality changes during the COVID-19 lockdown over the Yangtze River Delta Region: An insight into the impact of human activity pattern changes on air pollution variation Sci Total Environ 732:139282 doi:10.1016/j.scitotenv.2020.139282

8. S, Cai. H, Yang. Y, Cao. Y (2013) Advance in gray incidence analysis modeling Systems Engineering Theory \& Practice 33:2041-2046. (In china) 
9. $X$ (2017) Based on the hazard of nitrogen oxides and its prevention countermeasures Low carbon world:8-9. https://doi.org/10.16844/j.cnki.cn10-1007/tk.2017.09.006. (In china)

10. Morán J, Granada E, Míguez JL, Porteiro J (2006) Use of gray relational analysis to assess and optimize small biomass boilers Fuel Processing Technology 87:123-127 doi:10.1016/j.fuproc.2005.08.008

11. Nakada LYK, Urban RC (2020) COVID-19 pandemic: Impacts on the air quality during the partial lockdown in Sao Paulo state, Brazil Sci Total Environ 730:139087 doi:10.1016/j.scitotenv.2020.139087

12. Quirin $S$ (2020) Why pollution is falling in some cities - but not others Nature 580:313 doi:10.1038/d41586-020-01049-6

13. Sharma S, Zhang M, Anshika, Gao J, Zhang H, Kota SH (2020) Effect of restricted emissions during COVID-19 on air quality in India Sci Total Environ 728:138878 doi:10.1016/j.scitotenv.2020.138878

14. Wang Q, Su M (2020) A preliminary assessment of the impact of COVID-19 on environment - A case study of China Sci Total Environ 728:138915 doi:10.1016/j.scitotenv.2020.138915

15. M, Huang. Y (2015) Environmental pollution and economic growth in China China Economic Quarterly 14:557-578 doi:10.13821/j.cnki.ceq.2015.02.007. (In china)

\section{Figures}
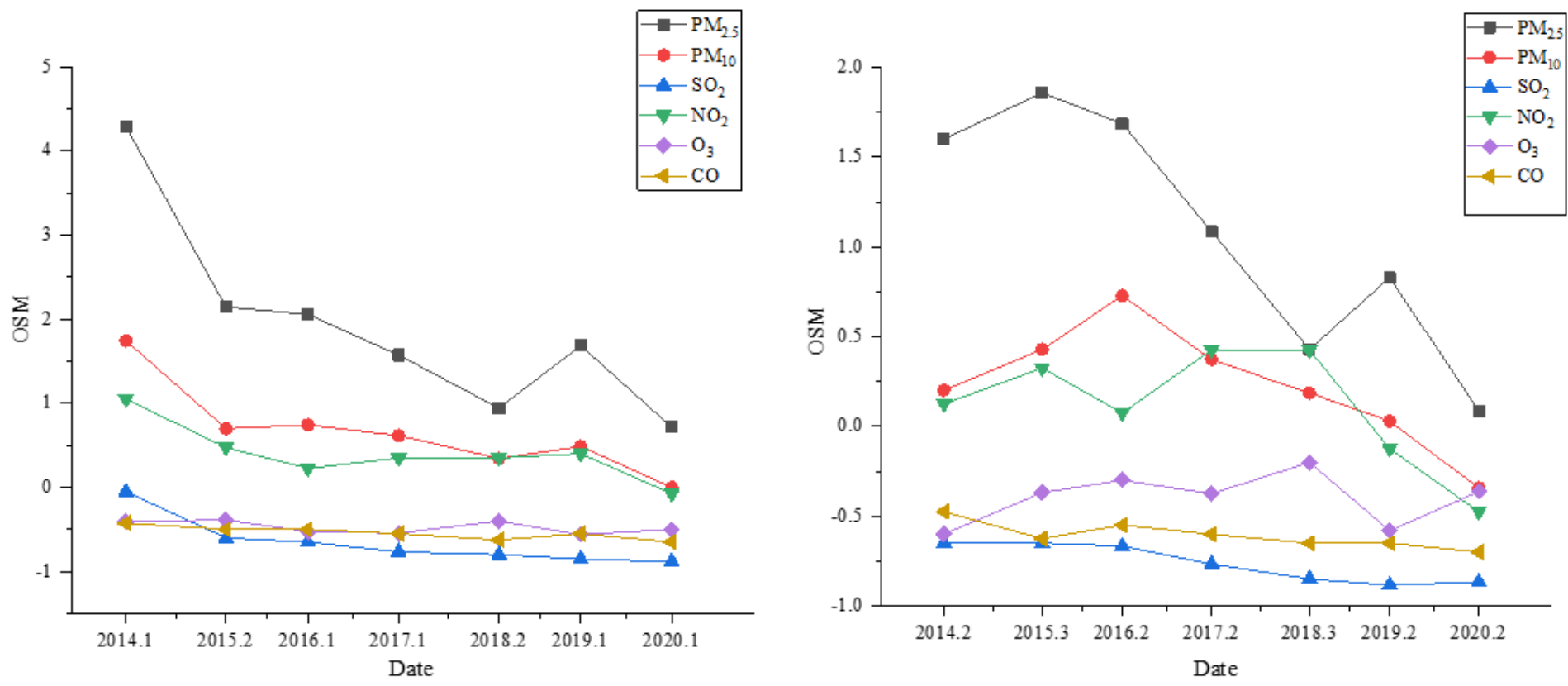

\section{Figure 1}

Changes in the GRD of PM in Wuhan during the same period in 2014-2020 


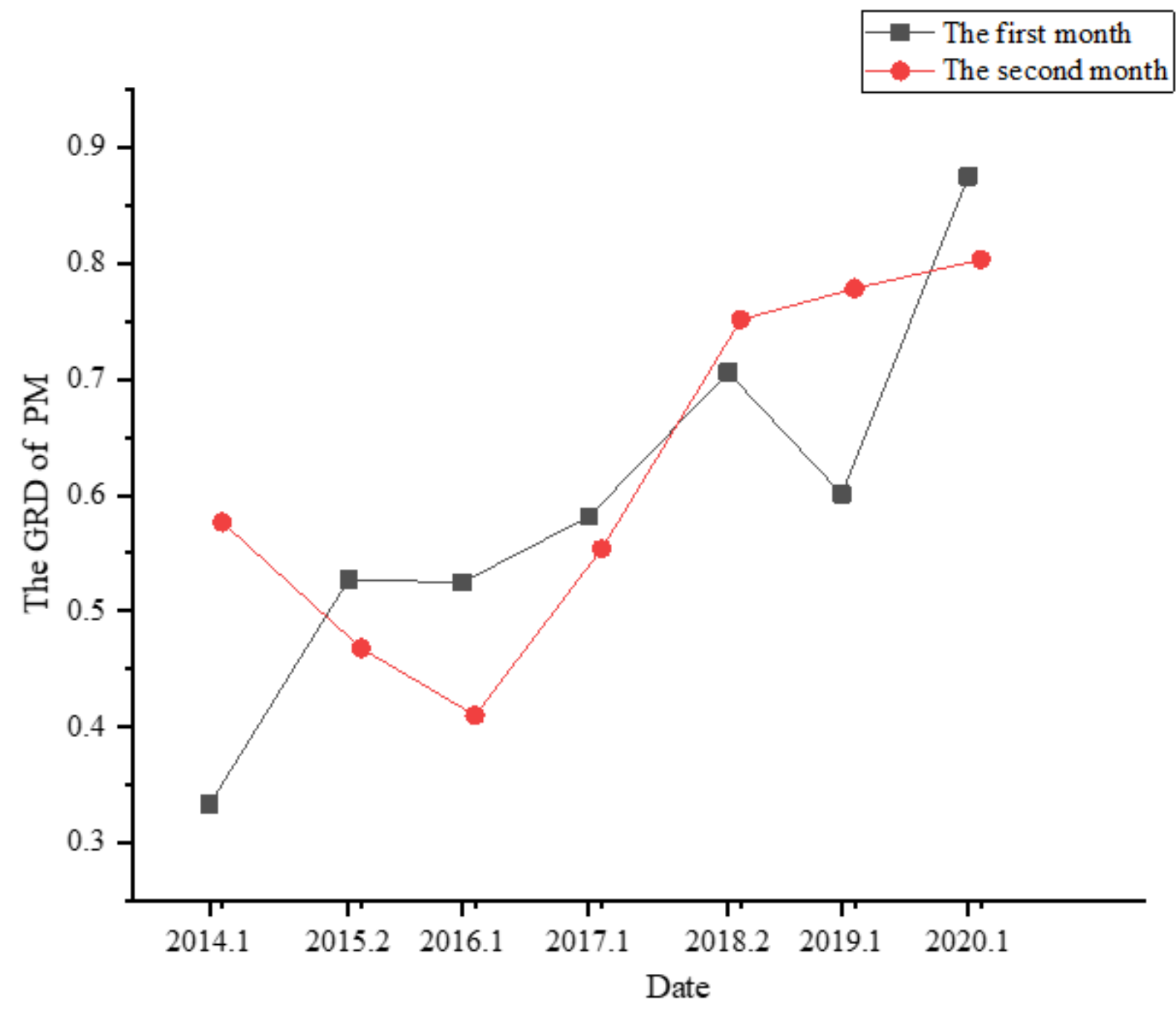

Figure 2

Changes of six pollutants' OSM in Wuhan during the same period in 2014-2020

\section{Supplementary Files}

This is a list of supplementary files associated with this preprint. Click to download.

- supplement1.xlsx 